\title{
Photo-Induced Thermally Stimulated Depolarization Current (TSDC) in Natural and Synthetic Alexandrite $\left(\mathrm{BeAl}_{2} \mathrm{O}_{4}: \mathrm{Cr}^{3+}\right)$
}

\section{Neilo Marcos Trindade ${ }^{1,2}$, Ana Regina Blak ${ }^{1}$, Elisabeth Mateus Yoshimura1, Luis Vicente de Andrade Scalvi ${ }^{3}$, Rosa Maria Fernandes Scalvi ${ }^{3}$}

${ }^{1}$ São Paulo Federal Institute, São Paulo, Brazil

${ }^{2}$ Institute of Physics, University of São Paulo, São Paulo, Brazil

${ }^{3}$ Department of Physics, São Paulo State University, Bauru, Brazil

Email: ntrindade@ifsp.edu.br

How to cite this paper: Trindade, N.M., Blak, A.R., Yoshimura, E.M., de Andrade Scalvi, L.V. and Scalvi, R.M.F. (2016) Photo-Induced Thermally Stimulated Depolarization Current (TSDC) in Natural and Synthetic Alexandrite $\left(\mathrm{BeAl}_{2} \mathrm{O}_{4}: \mathrm{Cr}^{3+}\right)$. Materials Sciences and Applications, 7, 881-894. http://dx.doi.org/10.4236/msa.2016.712067

Received: November 16, 2016 Accepted: December 11, 2016

Published: December 14, 2016

Copyright (c) 2016 by authors and Scientific Research Publishing Inc. This work is licensed under the Creative Commons Attribution International License (CC BY 4.0).

http://creativecommons.org/licenses/by/4.0/ (c) (i) Open Access

\begin{abstract}
The investigation of electrical properties in alexandrite $\left(\mathrm{BeAl}_{2} \mathrm{O}_{4}: \mathrm{Cr}^{3+}\right)$ in synthetic and natural forms is presented in this paper. Alexandrite is a rare and precious mineral that changes color according to the light incident on it. In the synthetic form, it is used technologically as an active laser medium. The electrical characterization was obtained using the Thermally Stimulated Depolarization Current (TSDC) technique, an interesting tool to study the behavior of impurities in insulators. Alexandrite presented the electric dipole relaxation phenomenon, both in natural and in synthetic samples. It was possible to observe TSDC bands for the synthetic sample at around $170 \mathrm{~K}$, and at around $175 \mathrm{~K}$ for the natural sample. Besides, photo-induced TSDC measurements were performed through the excitement of the samples by using a continuous wave argon laser. In addition, photoluminescence measurements were performed to verify in advance whether the laser light would be absorbed by the sample, and in order to complement the photo-induced TSDC measurements analysis. The results of photo-induced TSDC experiments have contributed to the understanding of the TSDC bands behavior: the results obtained with the technique suggest that there is an effective participation of $\mathrm{Cr}^{3+}$ ions in the formation of TSDC bands because they were more intense when the sample was exposed to the argon laser beam.
\end{abstract}

\section{Keywords}

Alexandrite, Chrysoberyl, Thermally Stimulated Depolarization Current (TSDC), Photoluminescence, Photo-Induced 


\section{Introduction}

Alexandrite is a variety of chrysoberyl crystal that contains chromium in its structure and presents the following chemical composition: $\mathrm{BeAl}_{2} \mathrm{O}_{4}: \mathrm{Cr}^{3+}$ [1] [2]. Brazil is one of the largest producers of natural alexandrite [2]; it belongs to families of gems of high economical and technological interest [3].

The technological importance of alexandrite has increased after 1974, when it was possible to use it in synthetic form as an active laser medium, with superior characteristics when compared to other types of media, with emission in the range between 700 and $800 \mathrm{~nm}$ [4]. The first scientists who suggested the possibility of application of synthetic alexandrite as laser crystals were Farrel in 1963 [5], but they were not successful in obtaining it in practice [6]. Bukin et al. first reported the alexandrite laser in 1978 [7]. The Q-switched alexandrite laser operates in the range of $755 \mathrm{~nm}$, near infrared emission spectrum. Its pulse lasts about $100 \mathrm{~ns}$, and its long wavelength allows deep penetration into the skin [8], so it is widely used in dermatology, as well as other popular lasers such as the Q-switched ruby (QSR) $(694 \mathrm{~nm})$ and Q-switched Nd:YAG laser (1064 $\mathrm{nm}$ and 532). There are many recent works showing applications of the alexandrite laser in medicine as in the treatment of facial and labial lentigines associated with Peutz-Jeghers syndrome [9], café au lait macules [10], seborrheic keratoses [11], hirsutism [12], trichostasis spinulosa [13] and other applications such as hair removal [14] and tattoos removal [15].

An important property is its color change according to light incident on it. If exposed to incandescent light, rich in red wavelengths, alexandrite has a red color. Exposing alexandrite to natural light, with a smaller portion in the red region of the spectrum, it generates shades of dominant blue-green color. This phenomenon is referred in the literature as alexandrite effect [16] [17]. The color change results in popularity and high market value of alexandrite as a gem. Furthermore, the alexandrite crystal is mechanically rigid and provides good thermal conductivity [18].

Figure 1 shows chrysoberyl structure. In chrysoberyl the unit cell contains four molecules with eight $\mathrm{Al}^{3+}$ ions (ionic radius $0.535 \AA$ ) occupying distorted octahedral sites, and four $\mathrm{Be}^{2+}$ ions $(0.47 \AA$ ) occupying distorted tetrahedral sites formed with oxygen ions located in planes perpendicular to the c-axis [19]. Due to the small ionic radius of

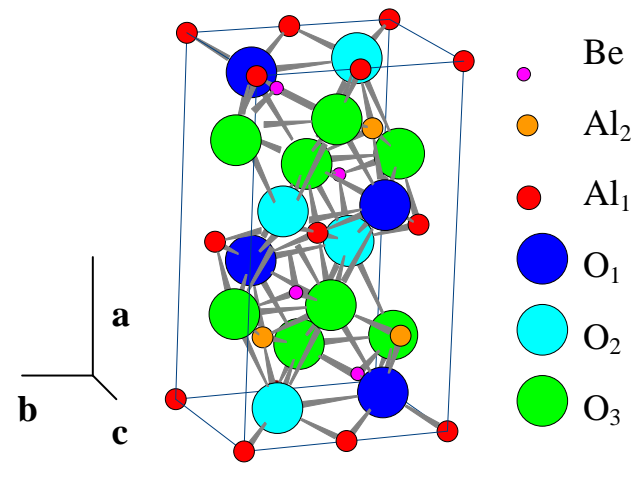

Figure 1. Chrysoberyl structure [4] [18]. 
$\mathrm{Be}^{2+}$, the crystal structure of chrysoberyl has a lower symmetry than the spinel mineral group with similar chemical formulas [20]. Such ionic radius also results in a bond length in the Be-O of $1.637 \AA$ [17]. Two of the three oxygen positions are located in a reflection plane and the third oxygen occupies a general position [20]. The chrysoberyl crystallization has an orthorhombic structure that corresponds to dense hexagonal packing, influencing the oxygen atom (atomic radius $2.7 \AA$ ) positions, which are slightly distorted by the presence of aluminum atoms. These distortions caused by aluminum give rise to two sites of different symmetries: a site, $\mathrm{Al}_{1}$, set in an inversion center (Ci symmetry) and a site, $\mathrm{Al}_{2}$, located in a reflection plane (Cs symmetry) [22] [23].

In two sites of different symmetries the $\mathrm{Al}^{3+}$ ions are replaced by $\mathrm{Cr}^{3+}(0.615 \AA)$ generating alexandrite. The larger site, named $\mathrm{Al}_{2}$, is preferably occupied by $\mathrm{Cr}^{3+}$ ions [18]. The octahedron containing $\mathrm{Al}_{2}$ sites, is regarded as larger than the $\mathrm{Al}_{1}$ octahedron, because the $\mathrm{Al}$-O bond length $\left(1.938 \AA\right.$ ) is wider at that site than at $\mathrm{Al}_{1}(1.890 \AA)$, resulting in a larger volume polyhedron [17]. According to literature, $\mathrm{Cr}^{3+}$ ions located in $\mathrm{Al}_{2}$ sites are responsible for the optical properties of alexandrite, including laser emission [24].

The electrical properties studied here can contribute to the understanding of the optical properties observed in alexandrite, such as the impurities aggregated in this crystal having diverse charge states.

\section{Materials and Methods}

The synthetic sample has been grown by H. P. Jenssen and R. Morris (from Allied Signal Inc., USA), by the Czochralski method [25]. Iridium crucibles, zirconia ceramic furnaces and $\mathrm{N}_{2}^{-} \mathrm{O}_{2}$ atmospheres were used, obtaining the following result: [001] oriented blades measuring about $1 \mathrm{~cm} \times 2 \mathrm{~cm}$ with $\mathrm{Cr}^{3+}$ substitutions of up to $0.3 \%$ atm (of $\mathrm{A} 1^{3+}$ sites) [26]. The sample faces were perfectly paralleled, with thickness of 2.33 $\mathrm{mm}$. Alexandrite rock pieces come from Minas Gerais state, Brazil, and show a dark green color. Samples have been cut in small pieces with thickness of $1.5 \mathrm{~mm}$.

The optical studies and electrical characterization of alexandrite can significantly contribute to the technological application of the material. The Thermally Stimulated Depolarization Currents (TSDC) technique successfully allows the understanding of the electric dipole relaxation mechanisms present in minerals [4] [27] [28] [29] [30] [31]. In addition, the TSDC technique can also be used in a modified manner, when the sample is photo-excited along with the electric field and then the effects on the material are analyzed.

Through one single measurement, the TSDC technique represents a very sensitive and accurate method for the determination of physical parameters such as relaxation time $(\tau)$, activation energy $\left(E_{a}\right)$ and dipole moment strength $(p)$ associated with defects with dipolar characteristics. Electric dipole characteristics are one of the requirements to detect the behavior of defects in solids using this technique [32]. The TSDC method consists of four basic steps: the sample is first polarized in an electric field $E_{p}$ for a time $t_{p}$, at temperature $T_{p}$. This temperature should be such that the dipoles can still be sta- 
tistically oriented with the electric field applied in a certain time $t_{1}$, and should not be so high that heavy space charge contributes to the signal. To ensure good polarization, dipoles must be polarized by a time $t_{p} \gg \tau\left(T_{p}\right)$. Then, in the second step, the temperature of the sample is reduced to $T_{o} \ll T_{p}$ so that the dipole relaxation time is long enough to prevent movements at low temperatures. At this stage, it can be said that the dipoles are "frozen" and statistically aligned with the applied field. After reaching $T_{o}$ (the liquid nitrogen temperature, in our experiment) the field is removed and an electrometer is connected to the sample (third step). After the initial capacitive discharge in the sample, it is heated at a constant rate $b=d T / d t$, and the current is recorded as a function of temperature in the final step of TSDC. The relaxation times become short and a current depolarization $i(T)$ is detected when the dipoles lose their preferential polarization orientation. During the time in which this process occurs, the current first increases exponentially, and continues increasing until a maximum value is reached; and then falls rapidly as Figure 2 illustrates. The physical process of TSDC measurement and behavior of dipoles presented in each step of the technique are also in Figure 2.

Previous to the measurement, the faces of the samples in contact with the electrodes are painted with silver paint to improve electrical contact for the application of electric field. The sample is polarized initially at room temperature and, after a first step to identify the TSDC peaks, the polarization is made near the peak of TSDC and an electric field is applied for a predetermined period of time in order to reduce the lattice contributions. After that time, the cryostat walls are put in contact with liquid nitrogen to produce a rapid temperature decrease. When the sample reaches a temperature of approximately $77 \mathrm{~K}$, the electric field is turned off. The same terminal is connected to an electrometer that will measure the depolarization current. When the current is stabilized, the sample is heated at $6 \mathrm{~K} / \mathrm{min}$, up to $300 \mathrm{~K}$. The polarization electric field is about $1.4 \mathrm{kV} / \mathrm{mm}$ value that considers the thickness of the sample.

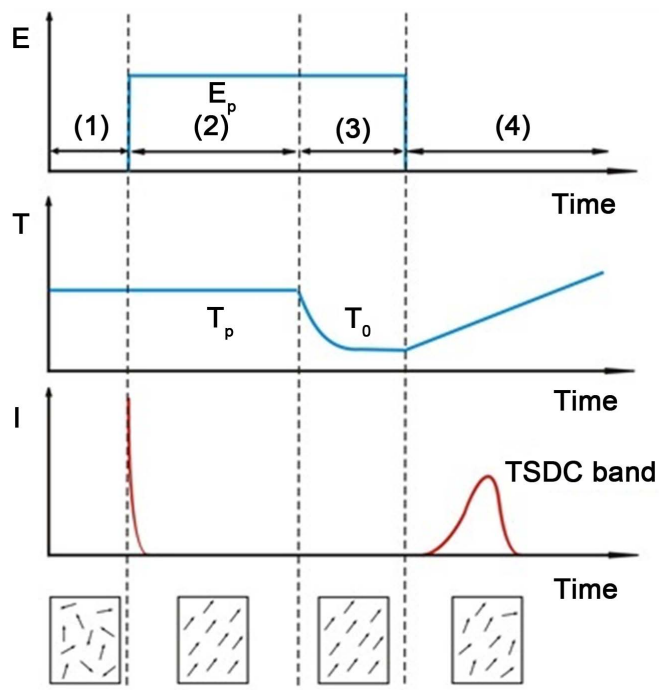

Figure 2. Physical process of TSDC measurements and behavior of dipoles. 
In measurements of photo-induced TSDC, the process is quite similar to the TSDC one. The scheme and steps of this method are shown in Figure 3. We have used two different methodologies to illuminate the sample, as explained next.

In the first process (i), in Figure 3, after the application of the electric field at a given polarization temperature (2), the temperature is decreased rapidly to a temperature close to $77 \mathrm{~K}$ (3). After removing the applied electric field, a laser beam is shined on the sample for a given time (4). The laser beam is removed and the temperature is increased at a constant rate, as usual. In this case, it is considered that the dipoles are already oriented and "frozen" when the laser is applied -we investigate the possible effect in this polarization direction with the incidence of laser beam in the material. In the second case (ii), in Figure 3, when the sample reaches a temperature close to $77 \mathrm{~K}$ (2), the electric field is applied together with the laser beam, but for different intervals (3) and (4). After removing the laser beam, the temperature is increased at a constant rate. In this case, it is considered that the dipoles are randomly oriented because they had not yet been "frozen" without the application of a previously bias field. This way, we seek to investigate the effect on these dipoles and if their orientation in these same conditions is possible with the absorption of photons of the laser beam.

The TSDC equipment makes use of a Janis Research VPF-100 model cryostat provided with transparent windows, high voltage source Keithley 248 High Voltage Supply model, a Lakeshore 321 temperature controller model, an electrometer Keithley 6517A model and a turbomolecular pump system Boc Edwards GI, 70H/E2M1.5/Ticcart model. The measurements were made using an automatic acquisition system data, the USB-6008 board 12-bit, $10 \mathrm{kS} / \mathrm{s}$ Multifunction I/O and NI-DAQmx software. To carry out the photo-induced TSDC measurements, an argon laser was used with beam di-
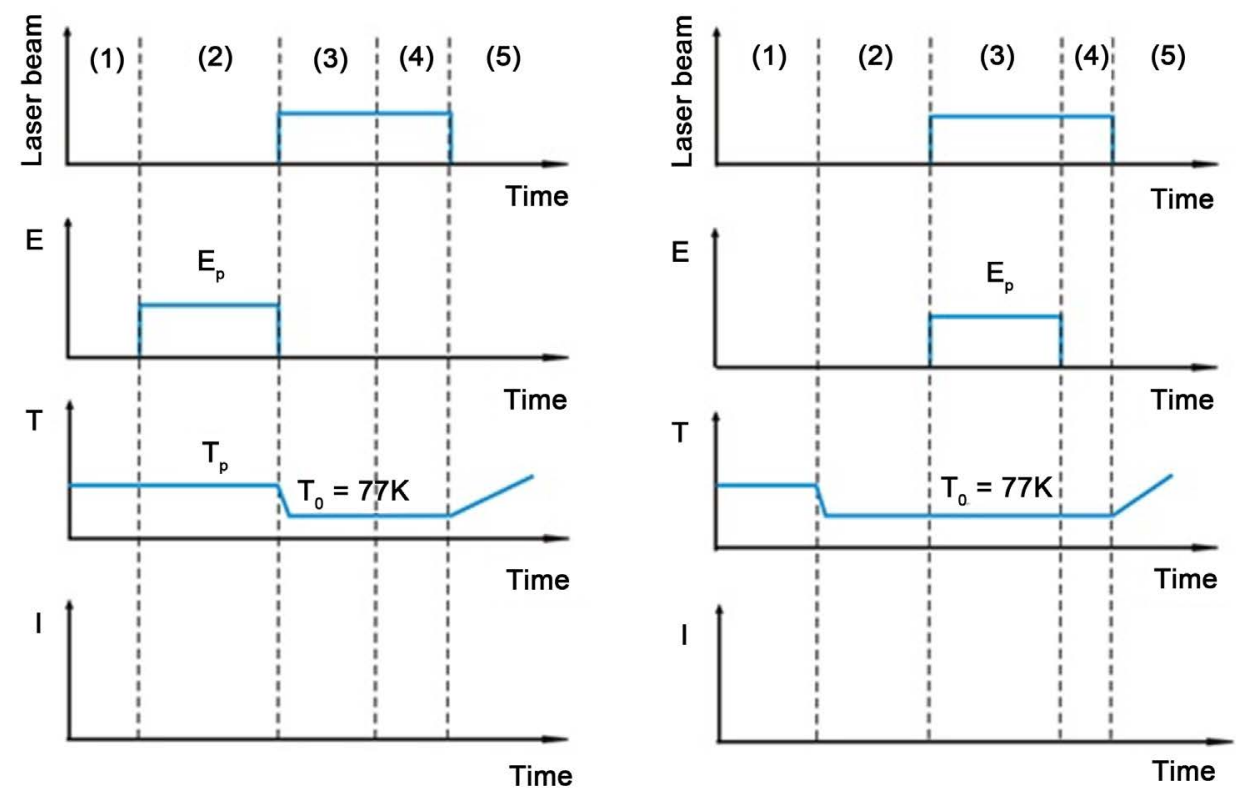

Figure 3. Scheme of photo-induced TSDC measurements, indicating the methods used: process i and process ii. 
rected to the sample by means of lenses and mirrors. Chemical analyses were performed using Scanning Electronic Microscopy (SEM), the Energy Dispersive (EDS) and Spectroscopy Wavelength Dispersive (WDS) techniques. The Argon laser emissions (Spectra 2017 model), with energy $\mathrm{h} v=2.51 \mathrm{eV}$, were used in the photoluminescence excitation and TSDC measurements. The light emitted by the sample is sent to the spectrometer and then to a detector due to the energy region where the measurement was made. The entire system is connected to a computer that controls the spectrometer and processes the data.

\section{Results and Discussion}

\subsection{Chemical Analysis}

Table 1 shows the results of two techniques (EDS and WDS) used to obtain the concentration of iron, aluminum and chromium contained in the sample. Both the techniques do not detect Be element due to its atomic number (smaller than 8 ).

The environment, the temperature and other important parameters of the natural materials forming process also influence the various types of impurities which may be incorporated in bulk rock, such as $\mathrm{K}, \mathrm{Si}$ and $\mathrm{Ca}$. The Table 1 results show that iron concentration is substantially larger compared to chromium. Moreover, iron can also be related to the color of alexandrite [17]. It is of great importance to highlight the presence of $\mathrm{Fe}$, which is verified due to the presence of inclusions in natural alexandrite. According to Weber et al. [17], based on chemical and geometric arguments, it is assumed that, in alexandrite originated from Russia, the $\mathrm{Fe}^{3+}$ ion replaces $\mathrm{Al}$ in octahedral sites in the structure once the tetrahedron Be site is too small for such replacement. It can also occur the replacement of $\mathrm{Al}^{3+}$ to $\mathrm{Fe}^{2+}$ with the locally distorted octahedral coordination and expanded in accordance with the large ionic radius of $\mathrm{Fe}^{2+}(0.750 \AA)$ compared with $\mathrm{Al}^{3+}(0.535 \AA$ ). Thus, the charge is compensated by the presence of $\mathrm{Ti}$ tetravalent in the alexandrite. Both bivalent and trivalent iron in different $\mathrm{Al}$ positions has a certain preference for the wider site, $\mathrm{Al}_{2}$. Furthermore, a refinement of the structure shows that most of the iron is trivalent, but a small amount of bivalent iron is also detected, and that the incorporation of iron occurs in $\mathrm{Al}$ sites. In the TSDC measurements, Fe bands are observed only in natural samples.

The $\mathrm{Cr}^{3+}$ ions in $\mathrm{Al}_{2}$ are responsible for the laser property and characterize the high probability of electric dipole transitions. The transitions in the magnetic dipole type $\mathrm{Cr}^{3+}$ ions in $\mathrm{Al}_{1}$ do not significantly contribute to the photoluminescence of the material and, furthermore, are excluded from the laser process, as well as reinforcing the non-

Table 1. Composition of natural alexandrite obtained through EDS and WDS analysis.

\begin{tabular}{ccc}
\hline Element & EDS (\%WT) & WDS (\%WT) \\
\hline $\mathrm{Al}$ & 76.45 & - \\
$\mathrm{Cr}$ & 0.09 & 0.13 \\
$\mathrm{Fe}$ & 0.44 & 0.61 \\
\hline
\end{tabular}


radiative processes, degrading the efficiency of the laser [6] [33]. For the photo-induced electrical characterization it is necessary to verify that the material shows luminescence in the same temperatures that occur polarization.

\subsection{Photoluminescence}

In the luminescence spectrum, the $\mathrm{Cr}^{3+}$ ions lines in $\mathrm{Al}_{2}$ are called $\mathrm{R}_{1}$ and $\mathrm{R}_{2}$, and the $\mathrm{Cr}^{3+}$ ions lines in $\mathrm{Al}_{1}$ are called $\mathrm{S}_{1}$ and $\mathrm{S}_{2}$. Figure 4 shows the separation of $\mathrm{R}$ and $\mathrm{S}$ lines both for the natural and synthetic samples. As experimentally verified and presented in literature [34] [35], $\mathrm{R}_{1}$ and $\mathrm{R}_{2}$ lines appear in precisely the same wavelength at $680.4 \mathrm{~nm}$ and $678.5 \mathrm{~nm}$, respectively, in both spectra, absorption and emission at room temperature and are associated with transitions from the ground state to the ${ }^{2} \mathrm{E}$ level. In the emission spectrum, the lines $S_{1}$ and $S_{2}$ appear at 695.8 and $689.9 \mathrm{~nm}$ positions as well as in the optical absorption as narrow lines at 655.7, 649.3 and $645.2 \mathrm{~nm}$.

Figure 4 shows the luminescence spectrum for synthetic and natural samples whose transitions in the reflection site ( $\mathrm{R}$ lines) are around $680 \mathrm{~nm}$ and $678.5 \mathrm{~nm}$, in the inversion site ( $\mathrm{S}$ lines) are around $695.5 \mathrm{~nm}$ and $690 \mathrm{~nm}$. The $\mathrm{R}$ line is assigned to the forbidden ${ }^{2} \mathrm{E} \rightarrow{ }^{4} \mathrm{~A}_{2}$ transition of $\mathrm{Cr}^{3+}[3]$. The $\mathrm{R}$ lines in the emission spectrum are more intense than the $\mathrm{S}$ lines because the spectrum is dominated by the transitions associated with $\mathrm{Cr}^{3+}$ ions in $\mathrm{Al}_{2}$ compared to $\mathrm{Cr}^{3+}$ ions in $\mathrm{Al}_{1}$ [3] [23] [35]. This result was clearly observed for the natural sample.

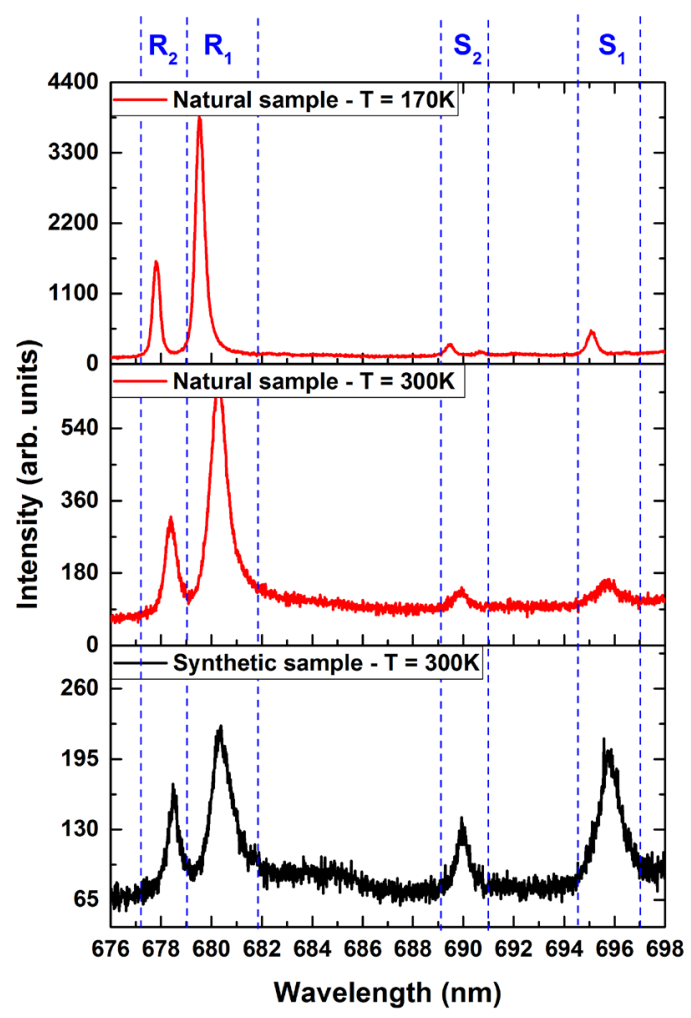

Figure 4. Photoluminescence spectrum of synthetic and natural alexandrite with exposure to argon laser $(488 \mathrm{~nm})$. 


\subsection{Photo-Induced Thermally Stimulated Depolarization Current}

Assuming that the source of the dipole is essentially the participation of $\mathrm{Cr}^{3+}$ ions, it is interesting to analyze the results of photo-induced TSDC measurements because these ions are responsible for emission lines in the photoluminescence spectra, and thus, we seek to investigate a photo-excited influence on the bands of TSDC. Regarding to electrical properties, according to the literature [4], the possible formation of dipoles in alexandrite is related to its crystalline structure. The structure has the $\mathrm{Al}_{1}$ and $\mathrm{Al}_{2}$ linked sites, each one with six oxygen atoms, three of which are independent and symmetrically designated $\mathrm{O}_{1}, \mathrm{O}_{2}$ and $\mathrm{O}_{3}$. The simple aforementioned replacement of $\mathrm{Cr}^{3+}$ to $\mathrm{Al}^{3+}$ in the structure would be able to cause the formation of dipoles. Nevertheless, the difference between the ionic radius $\mathrm{Al}^{3+}(0.535 \AA)$ and $\mathrm{Cr}^{3+}(0.615 \AA)$ in alexandrite can trigger the dipoles. It is also likely that the presence of oxygen vacancies leads to the presence of dipoles of impurity-vacancy type caused by different distances between $\mathrm{Cr}^{3+}$ and vacancy. One last possibility is the presence of other structure intrinsic defects, especially in the case of natural samples. The TSDC measurements were taken with a synthetic and a natural sample.

In photo-induced TSDC we used a high quality synthetic sample. The sample had already been polished and its faces parallel to each other, through which the electric field is applied. The sample was polarized for 7 minutes at room temperature with a $3300 \mathrm{~V}$. We chose to carry out the process (i), photo-induced TSDC. The measurement was repeated twice with exposure to argon laser, for equal periods of time, but with different powers, as shown in Figure 5.

In Figure 5, TSDC curve for synthetic sample shows a broad band with maximum intensity around $170 \mathrm{~K}$. We believe that above $230 \mathrm{~K}$ the results are not related to the effects of dipolar relaxation. It is likely that bands at these temperatures are due to a

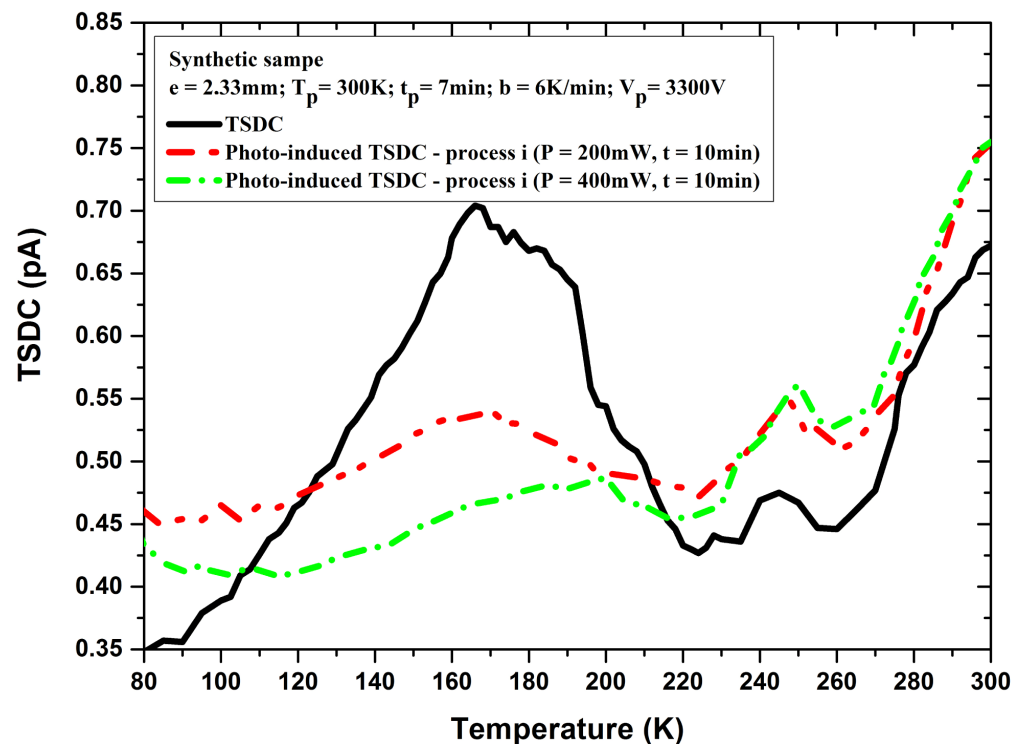

Figure 5. TSDC and photo-induced TSDC data for a synthetic sample, with exposure to argon laser $(488 \mathrm{~nm})$, in process $\mathrm{i}$. 
contact effect. It can be concluded from Figure 5 that the increase in the laser power, leads to the process of "destruction" of dipoles, as be the main band has a decreased area, which is the quantity related to the number of oriented dipoles. To that extent, it is also clear that the dipolar relaxation can occur by photo-excitation, and not only by a thermal process, which is also a process dependent on the power of the laser used.

In the case of a natural sample, it is important to determine the dependence of the relaxation dipolar process with the electric field the TSDC measurement. It was performed for four different values, $800 \mathrm{~V}, 1000 \mathrm{~V}, 1200 \mathrm{~V}$ and $1400 \mathrm{~V}$, shown in Figure 6.

In Figure 6, for natural sample, it can be seen that the area under the TSDC curve is proportional to the applied field, according to the picture inserted. The graph is consistent with the dipolar relaxation theory, with increasing voltage applied, there are an increased number of dipole relaxations, and, in turn, curves become more defined and the maximum intensity of current increases.

As for the synthetic sample, polarization was carried out similarly in natural samples, including the length of polarization time. Nevertheless, a $1400 \mathrm{~V}$ voltage value was applied in accordance with its thickness. In addition to analyze the consequences of photo-excitation, the photo-induced TSDC, process $\mathrm{i}$ and ii were performed. Figure 7 shows obtained result.

The photo-induced TSDC results, for same natural sample, it can be seen in Figure 7. In process i (Figure 3), an intense band with its maximum at around $175 \mathrm{~K}$ is observed.

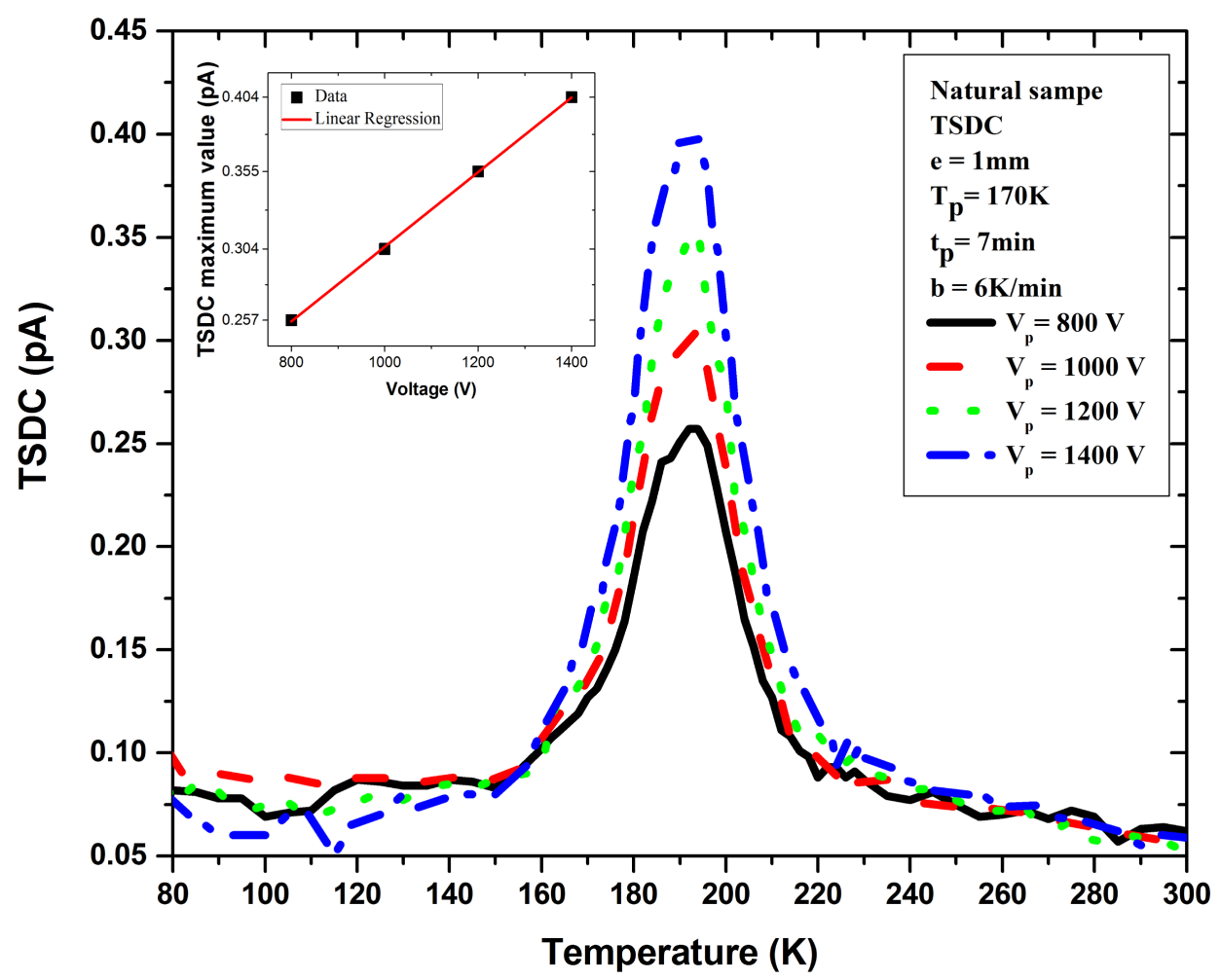

Figure 6. TSDC data for a natural sample, with application of four different voltages. The inset shows the linear dependence of TSDC maximum peak intensities with applied voltage. 


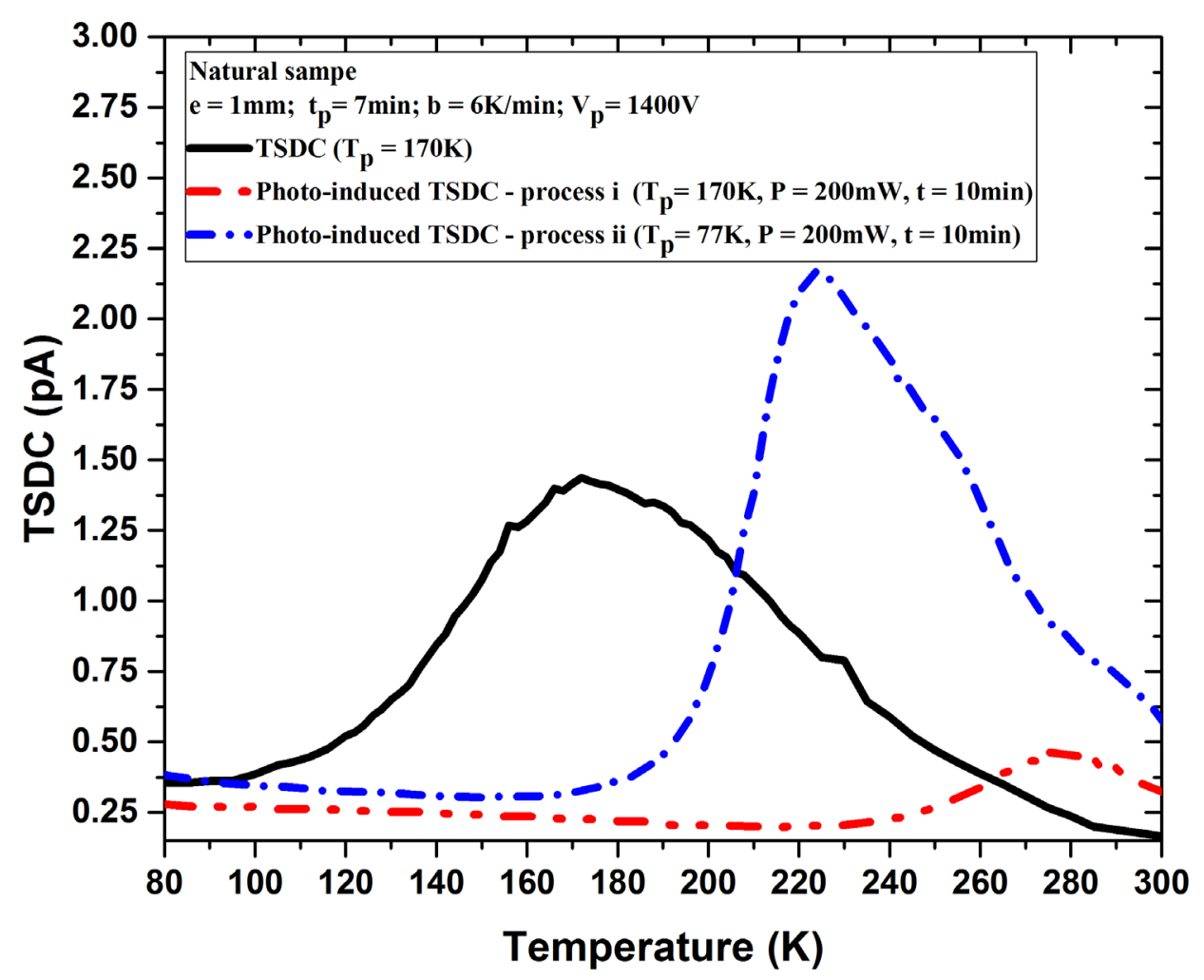

Figure 7. TSDC and photo-induced TSDC data for a natural sample, with exposure to argon laser $(488 \mathrm{~nm})$, in processes i and ii.

A comparison can be drawn between the power required to destroy the TSDC band in a natural and in a synthetic sample. The natural sample band at around $175 \mathrm{~K}$ disappears even with lower laser power $(200 \mathrm{~mW})$, whereas, the synthetic sample requires a larger power to do so. The process ii (Figure 3) was carried out using the same conditions, it is observed that this method promotes TSDC band for this sample with an intense band around $230 \mathrm{~K}$. We are convinced that this orientation of dipoles in low temperature (77 $\mathrm{K})$ by the laser light is possible, because of the synergism of the photon energies of the laser beams together with the applied electric field. Interestingly, it can be seen in these results that TSDC bands for natural samples are better defined and more intense at the maximum temperature than for synthetic samples. To understand these results, one should consider that in the natural samples there is presence of $\mathrm{Fe}^{3+}$ ions observed in optical absorption measurements in the spectral region of ultraviolet, and other additions such as $\mathrm{OH}$ and $\mathrm{SiO}_{4}$ can be seen in optical absorption measurements in the spectral infrared region [2]. These inclusions may lead to dipolar relaxation in the same temperature region, which is a $\mathrm{Cr}^{3+}$ and vacancy characteristic. Consequently, the TSDC band for these natural samples can be observed as a superposition of other bands of TSDC.

Regarding photo-induced measurements, it was observed that the process of destruction of TSDC bands in natural sample occurs more noticeably than in the synthetic one, which has dependence on the power of the applied laser. This result is in agreement 
with previous work [36] when it done to synthetic samples, and should contribute to the interpretation of results in natural samples presented in the literature. Also according to these authors, it is suggested that this process of destruction of TSDC bands does not occur for natural samples for they have irregular faces causing scattering of the light incident on it. Nonetheless, this work presents unprecedented results of destruction of bands in such samples. A small band around $280 \mathrm{~K}$ was also observed, which apparently is not influenced by laser presence and may be associated with contact effect.

\section{Conclusions}

The present work demonstrates that the material presents electric dipole relaxation phenomenon, both in natural and in synthetic samples. In this study, it was assumed that $\mathrm{Cr}^{3+}$ ions form dipole defects in the material. Chemical analysis of natural samples showed a large concentration of $\mathrm{Fe}$ in the material, predicted to be present in the $\mathrm{Al}_{2}$ site, which can interfere in the obtained results.

It was possible to observe TSDC bands for synthetic sample, around $170 \mathrm{~K}$, and around $175 \mathrm{~K}$ in natural sample. The TSDC experiment was performed with modification using an argon laser source, method called photo-induced TSDC. It was observed in the results that when the (i) process is carried out, the destruction of the TSDC band occurs in synthetic and natural samples. That way, you can disorient the dipoles at low temperature $(77 \mathrm{~K})$ and, consequently, most likely destroy TSDC bands at the temperature they occur, and to the synthetic sample it was found that there is a laser power dependence on the effective destruction of these bands. The result of the (ii) process shows that the incidence of the laser beam provides a more effective orientation of dipoles and, consequently, an increase in the intensity of TSDC band if compared to the situation without laser beam in natural samples.

These results of photo-induced TSDC suggest that there is an effective participation of $\mathrm{Cr}^{3+}$ ions in the formation of TSDC bands. This statement comes from the correlation between the measurements of electrical characterization and optical characterization of alexandrite. This is possible because the photoluminescence measurements confirmed the presence of $\mathrm{Cr}^{3+}$ emission lines with the incidence of the same laser used in photo-induced measurements. Another interesting fact was that the TSDC bands were more intense when the sample was exposed to the laser beam, thus promoting greater orientation of dipoles related to the presence of oxygen vacancies associated with $\mathrm{Cr}^{3+}$, and change local load due to substitution of $\mathrm{Al}^{3+}$ sites by $\mathrm{Cr}^{3+}$ ions.

Future efforts will be directed to thermoluminescence (TL) investigations of natural alexandrite. Thermoluminescence is the thermally stimulated emission originated from energy that was previously stored in the crystal during exposition to ionizing radiation. Initial measurements show that the alexandrite sample exhibits the TL peaks and it is likely that $\mathrm{Cr}^{3+}$ ions have an important part in this process.

\section{Acknowledgements}

Funding for this work was provided by Brazilian agencies FAPESP, CNPq and CAPES. 
The authors are grateful to Prof. Dr. Américo S. Tabata for use of the PL technique facilities and Mr. Luciano B. Ramos for language review.

\section{References}

[1] Rossi, M., Dell'Aglio, M., Giacomo, A., Gaudiuso, R., Senesi, G.S., Pascale, O., Capitelli, F., Nestola, F. and Ghiara, M.R. (2014) Multi-methodological Investigation of Kunzite, Hiddenite, Alexandrite, Elbaite and Topaz, Based on Laser-Induced Breakdown Spectroscopy and Conventional Analytical Techniques for Supporting Mineralogical Characterization. Physics and Chemistry of Minerals, 41, 127-140. https://doi.org/10.1007/s00269-013-0631-3

[2] Trindade, N.M., Scalvi, R.M.F. and Scalvi, L.V.A. (2010) $\mathrm{Cr}^{3+}$ Distribution in $\mathrm{Al}_{1}$ and $\mathrm{Al}_{2}$ Sites of Alexandrite $\left(\mathrm{BeAl}_{2} \mathrm{O}_{4}: \mathrm{Cr}^{3+}\right)$ Induced by Annealing, Investigated by Optical Spectroscopy. Energy and Power Engineering, 2010, 18-24. https://doi.org/10.4236/epe.2010.21004

[3] Ollier, N., Fuchs, Y., Olivier, C., Horn, A.H. and Rossano, S. (2015) Influence of Impurities on $\mathrm{Cr}^{3+}$ Luminescence Properties in Brazilian Esmerald and Alexandrite. European Journal of Mineralogy, 27, 783-792. https://doi.org/10.1127/ejm/2015/0027-2484

[4] Scalvi, R.M.F., Siu Li, M. and Scalvi, L.V.A (2005) Thermal Annealing-Induced Electric Dipole Relaxation in Natural Alexandrite. Physical and Chemistry of Minerals, 31, 733-737. https://doi.org/10.1007/s00269-004-0442-7

[5] Farrel, E.F., Fang, J.H. and Newham, H.P. (1963) Refinement of the Chrysoberyl Structure. American Mineralogist, 48, 804-810.

[6] Sevest'yanov, B.K. (2003) Excited-State Absorption Spectroscopy of Crystals Doped with $\mathrm{Cr}^{3+}, \mathrm{Ti}^{3+}$, and $\mathrm{Nd}^{3+}$ Ions-Review. Crystallography Reports, 48, 989-1011. https://doi.org/10.1134/1.1627442

[7] Bukin, G.V., Volkov, S.Y. and Matrosov, V.N. (1978) Optical Generation in Alexandrite $\left(\mathrm{BeAl}_{2} \mathrm{O}_{4}: \mathrm{Cr}^{3+}\right)$. Kvanttovaya Electronika, 5, 1168-1169.

[8] Torezan, L.A.R. and Osório, N. (1990) Laser in Dermatology: Physical Principles, Types and Indications. Brazilian Annals of Dermatology, 74, 13-20.

[9] Li, Y., Tong, X., Yang, J., Yang, L., Tao, J. and Tu, Y. (2012) Q-Switched Alexandrite Laser Treatment of Facial and Labial Lentigines Associated with Peutz-Jeghers Syndrome. Photodermatology, Photoimmunology \& Photomedicine, 28, 196-199. https://doi.org/10.1111/j.1600-0781.2012.00672.x

[10] Wang, Y., Qian, H. and Lu, Z. (2012) Treatment of Café Au Lait Macules in Chinese Patients with a Q-Switched 755-nm Alexandrite Laser. Journal of Dermatological Treatment, 23, 431-436. https://doi.org/10.3109/09546634.2011.590790

[11] Kim, Y.K., Kim, D.-Y., Lee, S.J., Chung, W.S. and Cho, S.B. (2014) Therapeutic Efficacy of Long-Pulsed 755-nm Alexandrite Laser for Seborrheic Keratoses. Journal of the European Academy of Dermatology and Venereology, 28, 1007-1011. https://doi.org/10.1111/jdv.12231

[12] Nilforoushzadeh, M.A., Naieni, F.F., Siadat, A.H. and Rad, L. (2011) Comparation between Sequentional Treatment with Diode and Alexandrite Lasers versus Alexandrite Laser Alone in the Treatment of Hirsutism. Journal of Drugs in Dermatology, 10, 1255-1259.

[13] Toosi, S., Ehsani, A.H., Noormohammadpoor, P., Esmaili, N., Mirshams-Shahshahani, M. and Moineddin, F. (2010) Treatment of Trichostasis Spinulosa with a 755-nm Long-Pulsed Alexandrite Laser. Journal of the European Academy of Dermatology and Venereology, 24, 470-473. https://doi.org/10.1111/j.1468-3083.2009.03448.x 
[14] Ibrahimi, O.A., Avram, M.M., Hankes, C.W., Kilmer, S.L. and Anderson, R.R. (2011) Laser Hair Removal. Dermatologic Therapy, 24, 94-107. https://doi.org/10.1111/j.1529-8019.2010.01382.x

[15] Saedi, N., Metelitsa, A., Petrell, K., Arndt, K.A. and Dover, J.S. (2012) Treatment of Tattoos with a Picosecond Alexandrite Laser. Archives of Dermatology, 148, 1360-1363. https://doi.org/10.1001/archdermatol.2012.2894

[16] Gubelin, E. (1976) Alexandrite from Lake Manyara, Tanzania. Gems \& Gemology, 15, 203209.

[17] Weber, S.U., et al. (2007) ${ }^{57}$ Fe Mossbauer Spectroscopy, X-Ray Single-Crystal Diffractometry, and Electronic Structure Calculations on Natural Alexandrite. Physics and Chemistry of Minerals, 34, 507-515. https://doi.org/10.1007/s00269-007-0166-6

[18] Collins, S.C., Wilkerson, T.D., Wilckwar, V.B., Rees, D., Walling, J.C. and Heller, D.F. (1997) The Alexandrite Ring Laser: A Spectrally Narrow Lidar Light Source for Atmospheric Fluorescence and Absorption Observations. In: Ansmann, A., Neuber, R., Rairoux, P. and Wandinger, U., Eds., Advances in Atmospheric Remote Sensing with Lidar, Springer Verlag, Berlin, 577-580. https://doi.org/10.1007/978-3-642-60612-0 140

[19] Scalvi, R.M.F., Ruggiero, L.O. and Li, M.S. (2002) Influence of Annealing on X-Ray Diffraction of Natural Alexandrite. Powder Diffraction, 17, 135-138. https://doi.org/10.1154/1.1428284

[20] Ivanov, V.Y., Pustovarov, V.A., Shlygin, E.S., Korotaev, A.V. and Kruzhalov, A.V. (2005) Electronic Excitations in $\mathrm{BeAl}_{2} \mathrm{O}_{4}, \mathrm{Be}_{2} \mathrm{SiO}_{4}$, and $\mathrm{Be}_{3} \mathrm{Al}_{2} \mathrm{Si}_{6} \mathrm{O}_{18}$ Crystals. Physics of the Solid State, 47, 466-473. https://doi.org/10.1134/1.1884706

[21] Bauerhansl, P. and Beran, P. (1997) Trace Hydrogen in the Olivine-Type Minerals Chrysoberyl, $\mathrm{Al}_{2} \mathrm{BeO}_{4}$ and Sinhalite, $\mathrm{MgAlBO}_{4}-\mathrm{A}$ Polarized FTIR Spectroscopic Study. Schweizerische Mineralogische und Petrographische Mitteilungen, 77, 131-136.

[22] Rabadanov, M.K. and Dudka, A.P. (1997) Comparative Structural Study of $\mathrm{Al}_{2} \mathrm{BeO}_{4}$ and $\mathrm{Al}_{2} \mathrm{BeO}_{4}: \mathrm{Cr}^{3+}$. Inorganic Materials, 33, 48-51.

[23] Trindade, N.M., Tabata, A., Scalvi, R.M.F. and Scalvi, L.V.A. (2011) Temperature Dependence Luminescence Spectra of Synthetic and Natural Alexandrite $\left(\mathrm{BeAl}_{2} \mathrm{O}_{4}: \mathrm{Cr}^{3+}\right)$. Materials Science and Applications, 2, 284-287. https://doi.org/10.4236/msa.2011.24037

[24] Shepler, K.L. (1984) Fluorescence of Inversion Site $\mathrm{Cr}^{3+}$ Ions in Alexandrite. Journal of Applied Physics, 56, 1314-1318. https://doi.org/10.1063/1.334119

[25] Guo, X., et al. (1987) Czochralski Growth of Alexandrite Crystals and Investigation of Their Defects. Journal of Crystal Growth, 83, 311-318. https://doi.org/10.1016/0022-0248(87)90292-2

[26] Walling, J.C., Peterson, O.G., Jenssen, H.P., Morris, R.C. and O’Dell, E.W. (1980) Tunable Alexandrite Lasers. IEEE Journal of Quantum Electronics, 16, 1302-1315. https://doi.org/10.1109/JQE.1980.1070430

[27] Cortezão, S.U. and Blak, A.R. (1998) Optical Absorption (OA) and Thermally Stimulated Depolarization Currents (TSDC) in Brazilian Amethyst. Radiation Effects and Defects in Solids, 147, 1-10. https://doi.org/10.1080/10420159808226381

[28] Cortezão, S.U. and Blak, A.R. (2000) Thermally Stimulated Depolarization Currents in Brazilian Amethysts. Brazilian Journal of Vacuum Applications, 19, 43-45.

[29] Cortezão, S.U., Pontuschka, W.M., Rocha, M.S.F. and Blak, A.R. (2003) Depolarisation Currents (TSDC) and Paramagnetic Resonance (EPR) of Iron Amethyst. Journal of Physics and Chemistry Solids, 64, 1151-1155. https://doi.org/10.1016/S0022-3697(03)00043-X

[30] Vismara, M.V.G., Trindade, N.M., Ruggiero, L.O. and Scalvi, R.M.F. (2008) Investigation of 
the Phenomenon of Electric Dipolar Relaxation in Brazilian Amethysts. Brazilian Journal of Vacuum Applications, 27, 43-49.

[31] Russo, F.T., Scalvi, R.M.F., Scalvi, L.V.A. and Vismara, M.V.G. (2012) Photo-Induced Dipole Relaxation Current in Natural Amethyst. Materials Research, 15, 461-466.

https://doi.org/10.1590/S1516-14392012005000052

[32] Chen, R. and Mckeever, S.W.S. (1997) Theory of Thermoluminescence and Related Phenomena. World Scientific, Singapore. https://doi.org/10.1142/2781

[33] Torizuka, K., Yamashita, M. and Yabiku, T. (1994) Thermal Effect in a Lamp-Pumped Continuous-Wave Alexandrite Laser. Journal of Applied Physics, 33, 1899-1904. https://doi.org/10.1143/JAP.33.1899

[34] Powell, R.C., Xi, L., Gang, X., Quarles, G.J. and Walling, J.C. (1985) Spectroscopy Properties of Alexandrite Crystals. Physical Review B, 32, 2788-2797.

https://doi.org/10.1103/PhysRevB.32.2788

[35] Suchocki, A.B., Gilliland, G.D., Powell, R.C., Bowen, J.M. and Walling, J.C. (1987) Spectroscopy Properties of Alexandrite Crystals II. Journal of Luminescence, 37, 29-37. https://doi.org/10.1016/0022-2313(87)90179-7

[36] Scalvi, R.M.F. (2000) Electric Dipolar Relaxation in Natural and Synthetic Alexandrite. PhD Thesis, University of São Paulo, São Carlos.

\section{Submit or recommend next manuscript to SCIRP and we will provide best service} for you:

Accepting pre-submission inquiries through Email, Facebook, LinkedIn, Twitter, etc. A wide selection of journals (inclusive of 9 subjects, more than 200 journals)

Providing 24-hour high-quality service

User-friendly online submission system

Fair and swift peer-review system

Efficient typesetting and proofreading procedure

Display of the result of downloads and visits, as well as the number of cited articles

Maximum dissemination of your research work

Submit your manuscript at: http://papersubmission.scirp.org/

Or contactmsa@scirp.org 